\title{
Emotional Intelligence and Its Impact Upon Learning and Teaching- A Case Study of a Teacher in Higher Education
}

\author{
Monika Gautam \\ Amity University Uttar Pradesh \\ Mala Tandon \\ Amity University Uttar Pradesh \\ Amita Bajpai \\ University of Lucknow
}

\begin{abstract}
Human beings are endowed with qualities and capabilities that make them unique in this world. Their intellectual capabilities help in solving problems, decision-making and creativity. Human beings also possess emotions that influence their well-being. According to Mayer and Salovey, Emotional Intelligence is the ability of individuals to perceive, use, understand and manage emotions. The researcher conducted a case study on a teacher of Higher Education in Lucknow, India to understand the impact of Emotional Intelligence on teaching and learning. Her Emotional Intelligence was assessed through Emotional Intelligence Scale of Hyde et al. Interaction was also done with the teacher, her students, colleagues and family. The result showed that she has high Emotional Intelligence. This is reflected in her interaction with students and colleagues. She efficiently manages intrapersonal emotions and interpersonal relationships. She ignites the desire for learning in the students; and also nurtures their Emotional Intelligence so that they are able to identify and manage their own emotions; and consequently, become prepared to face the challenges of the global world.
\end{abstract}

Keywords: Emotional Intelligence, higher education, role of teachers

\section{INTRODUCTION}

Human beings are endowed with many qualities and capabilities that make them highly evolved and unique in this world. The intellectual capabilities bestow upon them cognitive qualities like thinking, reasoning and analysis. These make them adept in solving problems, decision- making, creativity and scientific innovations. In addition to these, human beings also have emotions. For happiness, well being and success, it is very necessary that a person identifies his emotions, manages them and is also able to nurture interpersonal relationships. Here comes the role of Emotional Intelligence. In order to comprehend how the Emotional Intelligence of a teacher affects teaching learning and her interpersonal relationships, the researcher conducted a case study on a teacher of Higher Education in the city of Lucknow, Uttar Pradesh, India. 


\section{EMOTIONS}

All human beings possess emotions. No individual can be completely devoid of emotions. The emotions, whether positive or negative, play a very significant role in moulding the behaviour and personality of individuals. Emotions are believed to arise as a response to any internal or external event that may have either a positive or a negative meaning for an individual. These are a complex state of feelings that lead to physiological as well as psychological changes (Cherry, 2019). These changes affect the thinking and the behaviour of an individual person. According to David G. Meyers, emotions consist of 3 components- "physiological arousal, expressive behaviours and conscious experience" (Cherry, 2019). Emotions can be positive or negative. Primary emotions like love, happiness, fear and anger are innate and universal. Experiences help in the learning of secondary emotions like shame, pride, sympathy and empathy (The Main Theories of Emotions, 2019). The management of emotions requires the presence of Emotional Intelligence.

\section{EMOTIONAL INTELLIGENCE}

Mayer and Salovey (1997) have said that Emotional Intelligence is the ability to perceive, use, understand and manage emotions. They defined Emotional Intelligence as the "subset of social intelligence that involves the ability to monitor one's own and others' feelings and emotions, to discriminate among them and also use this information to guide one's thinking and actions." EI helps in the appraisal as well as the expression of one's feelings. It plays a very important role in the comprehension of the emotions that are present in the people around us. Emotional Intelligence helps in the regulations of the emotions present in one's own self and also affects the management of interpersonal relationships (Mayer, Salovey, Caruso, 2004). In 2007, Salovey, Bracket, \& Mayer stated that emotions were "organized responses" that crossed 4 subsystems of the brain. These subsystems are "physiological, cognitive, motivational, and experiential subsystems" (Hanscome, 2019; Mayer, Salovey, Caruso, Cherkasskiy, 2011).

The concept of Emotional Intelligence became very popular in 1995 when Daniel Goleman (Hanscome, 2019) published a book with the title 'Emotional Intelligence'. Goleman believed that EI was more important than the Intelligence Quotient for achieving success in life. His model consists of knowing one's own emotions, management of emotions, self- motivation, recognition of the feelings of others and managing relationships with others. Emotional Intelligence is the capability of processing emotional information with precision and efficiency. A person who is emotionally intelligent is capable of comprehending his own feelings and is also aware of how these emotions will affect other people (Hanscome, 2019; Mayer, Salovey, Caruso, Cherkasskiy, 2011; Culver, 1998; Pandey, 2007; Woolfolk, 2004)

The people with high level of Emotional Intelligence are self- aware and they know how to manage their emotions (Mayer, Salovey, Caruso, 2004). Other people enjoy their company, and they radiate positive vibes which lead to happiness and well- being. They are able to adjust well with others around them. Such people do not become slaves to their emotions. Emotional Intelligence includes skills that can be broadly grouped into personal and social competence. Personal competence includes awareness as well as management of one's emotions. Social competence is the ability of understanding the emotions of other people. It also includes the effective management of relationships. Some people are naturally endowed with high level of EI. Emotional Intelligence can also be developed with consistent efforts (Hanscome, 2019).

It is believed that Emotional Intelligence has a considerable influence on the performance and behaviour of people. It includes the skills of decision-making, communication, stress management, anger management, assertiveness, trust, empathy, time management, social skills, teamwork and the acceptance of change. A person who successfully manages his emotions and is also able to maintain positive relationships with other people is able to stay mentally and emotionally healthy (Hanscome, 2019; Chowdhury, 2020; Rampton, 2016; Signs of High and Low EQ). 


\section{REVIEW OF RELATED LITERATURE}

The researchers analyzed various studies and researches related to the present case study. Some of them are mentioned below:

Sidhu in 2014 analyzed the relationship that was present "between Emotional Intelligence and the performance of teaching professionals" in the Technical and Management Institutions of both public as well as the private Universities in the regions of Punjab, Haryana and Chandigarh. The researcher concluded that a significant and positive relationship was present between Emotional Intelligence and the Organization Commitment of the teachers (Sidhu, 2014).

In the year 2018, Narayan analyzed how Emotional Intelligence influenced the attitude towards work of teachers of mainstream schools. They used six tools including "Wong Law Emotional Intelligence Scale (WLEIS)", "Boyle's Teacher Stress Inventory" (1995) and "Teacher Sense of Efficacy Scale (TSE (2005). For the study, 514 teachers were selected from mainstream schools. The study showed that Emotional Intelligence had an important influence on their self-efficacy and the stress that was related with their job. It was observed that teachers with a high level of Emotional Intelligence experienced lower level of stress and were more dedicated towards their organization (Narayan, 2018).

Ashu conducted a study in 2019 on the professional commitment and effectiveness of 200 teacher educators in relation to their emotional as well as spiritual intelligence in the state of Haryana. The tools used were "Professional Commitment Scale for Teacher Educators" of Vishal Sood; "Teacher Effectiveness Scale" prepared by Shallu Puri and S.C. Gakhar and "Emotional Intelligence Scale" developed by Hyde, Pethe and Dhar. The study highlighted that the correlation present between professional commitment and Emotional Intelligence as well as the correlation present between "professional commitment" and Spiritual Intelligence of the teacher educators were significantly positive. The researcher concluded that the correlation present between the effectiveness of the teacher educators and Emotional Intelligence was not significant ( Ashu, 2019).

In 2020, Sarani, Mousavi et al. analyzed the relationship that was present between "Emotional Intelligence and Self Efficacy" among the deputy's administrative staff of Kerman University of Medical Sciences, Kerman, Iran. A descriptive-correlational design was used. The research was conducted on 275 participants. The researchers concluded that a positive as well as a significant relationship existed between "Emotional Intelligence and self-efficacy" in the administrative personnel (Sarani, Mousavi, Salahi et al.,2020).

\section{JUSTIFICATION OF THE STUDY}

The researcher conducted review of many research studies but did not find any case study that was done on a teacher of Higher Education to deeply evaluate her/his Emotional Intelligence and its impact upon the teaching learning process. In order to comprehend how Emotional Intelligence of a teacher affects her/his performance in the teaching world, the researcher conducted a case study on a teacher of Higher Education in the City of Lucknow, Uttar Pradesh, India. This study would help to provide a deep insight into how an Emotionally Intelligent teacher can positively influence the teaching- learning and holistic development of the students.

The modern globalized world demands that the students, especially those of Higher Education, who step in the professional world, are both cognitively and emotionally intelligent. For the preparation of such individuals, teachers themselves have to enhance their Emotional Intelligence and should know how to manage their emotions and should positively manage their interpersonal relationships also. It is the need of the hour that teachers should nurture the capability of the students in the cognitive sphere as well as enhance their Emotional Intelligence.

The present case study fulfills the purpose and necessity to comprehend the impact of Emotional Intelligence on learning and teaching in Higher Education. 


\section{INTRODUCTION TO THE CASE}

Dr. Srishti Kapoor (Name changed for confidentiality) is an Associate Professor in the Faculty of Science and is Head of a Department in Higher Education. She is NET qualified and was awarded research fellowship. Dr. Kapoor is proficient in French. She has more than 30 years of experience in the field of teaching and research. Many research papers and popular science articles have been published by her. Dr.Kapoor has participated and presented research papers in National and International seminars/Conferences/Workshops. She has administrative experience also as the NSS Program Officer, Assistant Superintendent Examinations (Conduct and Checking); Member, Admission Committee; Member of Board of Studies and Subject Expert for Selection Committee for Lecturer in Senior Grade.

The researcher requested Dr. Srishti Kapoor to participate in the present study. She willingly agreed to help on the condition that her name will not be disclosed.

\section{METHODOLOGY}

The researcher conducted Descriptive type of Research and used intrinsic Case Study Method The study was conducted on a teacher of Higher Education in the city of Lucknow, Uttar Pradesh, India. The case was selected by purposeful sampling. The inclusion criteria were her rich experience in the teaching profession, her willingness to participate in the study and availability over a period of time. The researcher kept all the ethical considerations in mind during the present case study. The ethical moral code was earnestly and diligently followed. The data was collected by using a questionnaire, personal interviews and feedback given by the students and colleagues. The score obtained in the Emotional Intelligence Tool was carefully analyzed in accordance to the instructions and norms mentioned in the Manual. The data and information obtained from the interviews and feedback from Dr. Kapoor herself and her students, colleagues and family members were corroborated and objectively analyzed.

The researchers used the following methods to collect the relevant information and data:

\section{Emotional Intelligence Tool of Anukool Hyde, Sanjyot Pethe, Upinder Dhar}

The researcher used this tool for the assessment of Emotional Intelligence of the subject. There are 34 questions in this tool. The questions are based upon 10 factors. These factors are "self-awareness, empathy, self-motivation, emotional stability, managing relations, integrity, self-development, value orientation, commitment and altruistic behavior." This tool has a reliability of 0.88 . In order to obtain the validity from the coefficient of reliability, the reliability index was calculated. This was 0.93 which implies high validity.

\section{Interaction With Students, Colleagues and Family of Dr. Srishti Kapoor}

The researcher interacted with the students, colleagues and family members of Dr Srishti Kapoor to collect information like the behaviour, decision making skills, interpersonal relationships of the subject.

\section{Interaction With Dr. Srishti Kapoor}

The researcher personally interacted with Dr. Srishti Kapoor and tried to understand her views on interpersonal relationships, management of emotions and how she interacts with the students, colleagues and other people.

\section{RESULTS OBTAINED}

Result Obtained in the Emotional Intelligence Tool of Anukool Hyde, Sanjyot Pethe, Upinder Dhar

The subject obtained a score of 142 in the Emotional Intelligence Tool of Anukool Hyde, Sanjyot Pethe, Upinder Dhar. According to the manual, this implies that Dr.Srishti Kapoor has very high Emotional Intelligence. The results showed that she is self- aware and has confidence in her own self. Dr. Kapoor continues to do what she believes in even when her acts are criticized by others. She has good rapport and interpersonal relationship with her colleagues at workplace. Dr.Srishti Kapoor is empathetic and pays 
attention to the problems, worries and concerns of others. She makes efforts to understand the perspective of the others. Even under pressure, she continues to stay completely focused on the particular tasks she was doing. She is self-motivated and knows that people consider her as a source of inspiration. She maintains a balance between emotions and reasons. This helps her to make wise decisions. She makes an assessment of the situation and then acts. Even when there are disturbances, she can remain focused on the present task and believes that feelings should be managed.

According to the results obtained in the Emotional Intelligence Tool, Dr. Srishti Kapoor is emotionally stable. She remains composed in all types of good and bad conditions; and works for the accomplishment of goals even when obstacles and setbacks come up. She readily accepts new ideas and information. She encourages others to work under all circumstances but does not depend upon others for encouragement to perform well and sees the brighter side of all situations. She is considered to be of a friendly nature and she manages relationships properly. Dr. Srishti Kapoor is a woman of integrity and stands up for her beliefs. She is also aware of her weaknesses. She believes in self-development and makes efforts in this direction even when this is not demanded by her job. She strongly maintains the standards of honesty and believes in standing up against the unethical actions of others. This clearly shows that she has high value-orientation. Dr. Kapoor is organized and careful in her work and meets commitments. She is altruistic and motivates others to take initiative. She is adept in managing conflicts around her.

\section{Interaction With Colleagues, Students and Family}

The researcher interacted with some colleagues and students of Dr. Srishti Kapoor. Some of her students are working as teachers in different Educational Institutions and Universities. Their names are not being mentioned here so as to maintain the confidentiality of the identity of the people contacted. One of her students who is presently teaching in a University said that Dr. Srishti Kapoor is a soft-spoken person; and maintained good relationships with others around her. She is a great mentor and efficiently guides her students in different areas. Any student who had any problem, usually approached Dr. Kapoor as they knew that she will help and find a solution for their problem. Another student added that she is a very helpful teacher and has a friendly nature. She always motivates the students to progress in life. In general, the students said that Dr. Srishti Kapoor is very honest, humble and has good knowledge about her subject which she teaches very well. Her teaching style is also very good. She is very punctual and disciplined. Some of them mentioned that she sometimes becomes strict also. The students appreciated her confidence and added that she was very open minded and came up with new ideas. Some students added that while teaching she enriched the class with examples from her life- experiences and also from the real life. Dr. Srishti Kapoor shared with the students the problems that she herself faced when she was studying and also explained how she overcame them. This had a very positive impact on the students who were motivated to solve their problems with determination and perseverance. Another student appreciated her decisionmaking ability. Her decision-making is far sighted. She takes decisions after proper thinking and thus these decisions are readily accepted by her colleagues and students without any criticism.

The students considered her as a source of positivity due to which students reached out to her for help whenever required. They found her very optimistic who would interact politely even if something went wrong. Other students also appreciated that in every situation her behaviour and reactions revolved around 'hope'. A student said that she was a mother-like figure and also acts as a nutritionist who would guide the students about what to eat and what not to eat. She had her own opinion on life but also respected the opinion of others. In addition to teaching academics, she also taught values to her students. Another student, who is a faculty in a University, added that Dr. Srishti Kapoor is very hardworking. She never loses her temper. She is simple and far sighted and is emotionally strong. Some students added that many students consider her as their role model. The students find her very kind-hearted, calm-minded, impartial, empathetic and down to earth. She gives freedom to students to ask questions which she answers with proper specifications and without getting angry. She also maintains a good balance between her professional and personal lives.

Her colleagues said that Dr. Srishti Kapoor is intelligent, curious, polite and soft spoken who was always ready to help others. She did her duties honestly. She always encouraged her colleagues and is very 
supportive. She guides the junior faculty in the performance of their duties. Another student of Dr. Kapoor, who is presently a faculty in a University, added that Dr. Kapoor is very hardworking, disciplined, wise, kind, dignified and compassionate. She has a progressive mindset and is both inspirational and motivational for others. She is well versed in her subject. She makes quick, clear and wise decisions. The Head of another Department added that Dr. Srishti Kapoor is very simple, down to earth, honest and independent.

The non -teaching staff also said that Dr. Srishti is very supportive and caring for all. She is very punctual - in fact she came well before the scheduled time to the department so that classes could be commenced well in time. As the Head of the Department, she is a tough administrator and ensures that all the tasks of the department are performed effectively and fully. She shares a very strong bond of love and long- lasting relationship with her students as well as colleagues.

\section{Interaction With Dr. Srishti Kapoor}

The interaction with Dr. Srishti Kapoor was very enlightening. She has very realistic self-concept. She freely shared her journey in the teaching world. She said that she performed her duties very honestly and was proud of whatever she had achieved in her life. She added that the learning process goes on in life. An individual has to be willing and humble to learn from anybody. She said that she had learnt many things from her experiences. She learnt how to control and manage her emotions. When she started working as a teacher, she faced some difficulties and learnt that in addition to being professional in life, one should also be polite and compassionate with people around her. Going down the memory lane, Dr. Kapoor recalled that she was very strict. Gradually, she observed her senior colleagues and learnt that one should not shout at the students and the non-teaching staff but should first try to find out the reason for the undesirable behaviour and then should decide about what necessary steps should be taken for ensuring that such behaviour is not repeated.

Dr. Kapoor added that she learnt in the initial years of her service that it is very important to manage emotions wisely and to make concerted and purposive efforts to develop positive interpersonal relationships with students, colleagues, non-teaching staff and the management. This learning proved very fruitful for her and she nurtured very good interpersonal relationships with others. During the interview, Dr. Srishti Kapoor added that having good academic knowledge is very important for teachers; but it is equally important to learn to become emotionally strong and to harness the quality of understanding the emotions of others. She believes that when there is an emotional bonding present between individuals then a better relationship develops between them. Such people share their emotions with others and also enjoy working together as a team for the achievement of goals. As a teacher, she imbibed the habit of becoming aware of her own emotions and also being alert to the emotions of other individuals.

Dr. Srishti said that earlier she used to become very disturbed when anybody criticized her. But over a period of time she gradually learnt the skill of emotional management. She realized that it is wiser to accept criticism in a positive manner; and the criticism should be utilized for bringing improvement in oneself. Ego always acts as a hurdle in relationships. Therefore, one should always make efforts to keep oneself away from ego. She added that good relationships develop when one is willing to listen to what the other person is trying to communicate without any bias.

A teacher should learn to appreciate others, especially students, and to motivate them to make constant efforts to progress further. One should be open and receptive to the views as well as the problems of the students as these students look up to the teachers for guidance and help. A teacher has a very significant role in the holistic development of students. So, it is the duty of a teacher not only to enrich the students with cognitive knowledge but to imbibe in them the skills and values that will prepare them to face the challenges of life. A teacher who is open-minded and an active listener is very instrumental in ensuring the all-round development of the students. The teachers should always be very empathetic towards the students. When a teacher herself is able to identify and manage her own emotions appropriately and is able to perceive as well as understand the emotions of others, she will be able to motivate the students to be emotionally strong also. 


\section{DISCUSSION}

Dr. Kapoor has a score of 142 in the Emotional Intelligence Tool of Anukool Hyde, Sanjyot Pethe and Upinder Dhar. According to the instructions and norms written in the manual of this tool, she has high Emotional Intelligence. She consciously balances between emotions and reason. She remains composed during disturbances, is confident, self-motivated, humble and open-minded. She makes purposive efforts to remain emotionally strong and never allows her emotions to inundate her. The feedback given by her students, colleagues and family further confirms that she nurtures good relationships with her students, colleagues and other people. She understands the feelings, thoughts and needs of her students. This helps her to nurture good teacher-students relationship that positively influences the teaching-learning process. The students willingly listen and trust her as a well-wisher and confide in her whole-heartedly. She plays a very important role in enhancing the cognitive and creative abilities of the students; and also inculcates various life-skills in them so that the students develop holistically. Due to her positive disposition, empathy and willingness to help others, Dr. Kapoor succeeds in becoming a role model, especially for the students, who look up to her for guidance in different areas. As an optimist, she is motivating the students to never give up hope, stay focused on the road of progression and life-long learning and strive to achieve their goals fully in life.

A teacher in the modern globalized world needs to guide the students in such a manner so as to ensure their all-round development. Her or his behavior and attitude influences the students profoundly. The ways in which teachers manage their own emotions and also their interaction with others has a deep impact upon the students. In today's extremely competitive times students are under tremendous pressure to excel. Success is no guarantee even after a lot of efforts. Sometimes students succumb to pressure and may take the drastic and extreme step of taking one's own life or the life of any other person. This often happens because they are not able to effectively manage their own emotions and do not know any person who can guide them about how to understand and manage their emotions. The role of a teacher is not just to transfer knowledge and information; but she/he has to be a mentor and guide. Only a teacher who is highly emotionally intelligent herself/himself can actually succeed in guiding students in the positive management of emotions.

\section{IMPLICATIONS OF THE CASE STUDY}

The present case study highlights the role and significance of Emotional Intelligence in the world of teaching. It is very important that teachers nurture their Emotional Intelligence as this influences the relationships that a teacher has with students, colleagues, administrative officials and the non- teaching staff. Teachers are supposed to be role models. Students learn what they are taught by their teachers. In addition to this, they also learn by observing the actual behavior and actions of the teachers. It becomes the duty of teachers to act like a catalyst in helping the students nurture their Emotional Intelligence. A teacher who manages her emotions positively does not transfer the impact of her negative emotions, if any, on the students. Such teachers are active listeners to the problems of the students and act like a guiding star. They are ready to hear their perspective on issues with an open mind. Every student in the class is unique and needs to be given the opportunity to express his/her thoughts and ideas. The teachers who have high Emotional Intelligence succeed in managing stress; and do not display violent outbursts of temper.

In the recent past, the cases of suicides by students are constantly increasing due to many reasons. Students often end their lives due to the failure to face the challenges of life and the inability to manage emotions in a positive manner. It is the responsibility of teachers not only to remain emotionally intelligent but also to nurture the essential life skills in the students. This includes making all the students capable of management of their own emotions and also the development of rich interpersonal relationships. Such relationships will help in the sharing of even those feelings which, if left unexpressed, may lead to undesirable consequences.

This study provides an in-depth knowledge about how a highly emotionally intelligent teacher can positively influence the people around her. It highlights that a good teacher should not only ignite the desire 
for learning in students but should also help them to actualize their true potential and ensure their holistic development. Teachers are the guides, mentors and role models for the students. They should make concerted efforts to enhance their Emotional Intelligence. They should learn to identify as well as manage their own emotions and should not transfer the negative impact of their undesirable emotions on the students. Teachers should also motivate and guide the students so that they themselves are able to identify and manage their own emotions.

\section{CONCLUSION}

Teachers have a major responsibility of preparing the students for the future. They should not only enhance their academic expertise but should nurture their Emotional Intelligence also. The student-teacher bonding helps in the development of a relationship that is rich in trust and empathy. This is instrumental in the development of a conducive environment for life-long learning. An Emotionally intelligent teacher is able to manage personal emotions, motivates others to manage their emotions in an appropriate manner and nurtures good interpersonal relationships. It is very relevant that teachers should enhance their Emotional Intelligence so that they remain emotionally strong themselves and are also able to make a positive impact on preparing students to face the challenges of life.

In the words of Brad Henry (Celebrating World Teachers Day):

"A Good Teacher can inspire hope, ignite the imagination and instill a love of learning."

\section{ACKNOWLEDGEMENTS}

The authors acknowledge and appreciate the cooperation extended by Dr. Srishti Kapoor, her students, colleagues and family members during the research.

\section{REFERENCES}

Ashu. (2019). Professional Commitment and Effectiveness of Teacher Educators in relation to their Emotional and Spiritual Intelligence. Ph.D. Thesis. Kurukshetra University, Kurukshetra, Haryana. Retrieved from http://hdl.handle.net/10603/286843

Best, J.W., \& Kahn, J.V. (2009). Research in Education (10th Edition). New Delhi: PHI Learning Private Ltd., 19, 259-261.

Cherry, K. (2019). Overview of the 6 Major Theories of Emotion. Retrieved from https://www.verywellmind.com/theories-of-emotion-2795717

Chowdhury, M.R. (2020). How to Improve Emotional Intelligence through Training. Retrieved from https://positivepsychology.com/emotional-intelligence-training/

Culver, D. (1998). A Review of Emotional Intelligence by Daniel Goleman: Implications for Technical Education. Retrieved from http://archive.fie-conference.org/fie98/papers/1105.pdf

EQI. (n.d.). Signs of High and Low EQ. Retrieved from https://eqi.org/signs.htm

Exploring your mind. (2019). The Main Theories of Emotions. Retrieved from https://exploringyourmind.com/the-main-theories-of-emotions/

Hanscome, J. (2019). How does Emotional Intelligence Create a Culture that Promotes Diversity and Inclusion in the Workplace? Retrieved from https://granite.pressbooks.pub/ld820/chapter/3/

Hyde, A., Pethe, S., \& Dhar, U. (2011). Emotional Intelligence Scale. Agra: National Psychological Corporation.

KUMON. (2015). Celebrating World Teachers Day. Retrieved from https://www.kumon.co.uk/blog/celebrating-world-teachers-day/

Mayer, J.D., Salovey, P., \& Caruso, D.R. (2004). Emotional Intelligence: Theory, Findings and Implications. Psychological Inquiry, 15(3), 197-215. Retrieved from https://aec6905spring2013.files.wordpress.com/2013/01/mayersaloveycaruso-2004.pdf 
Mayer, J.D., Salovey, P., Caruso, D.R., \& Cherkasskiy L. (2011). Emotional Intelligence. Retrieved from http://citeseerx.ist.psu.edu/viewdoc/download;jsessionid=6AB55C0D5C8AB6B1B39018FBB67 DD2FB?doi=10.1.1.385.1776\&rep=rep1\&type=pdf

Narayan, P.R. (2018). Effect of Emotional Intelligence on Work Attitudes Among Mainstream School Teachers and Special Educators. [Ph.D. thesis]. Retrieved from http://shodhganga.inflibnet.ac.in:8080/jspui/handle/10603/261209

Pandey, K.P. (2007). Advanced Educational Psychology (p.440). Varanasi: Vishwavidyalaya Prakashan. Rampton J. (2016). 10 Qualities of People With High Emotional Intelligence. Retrieved from https://www.inc.com/john-rampton/10-qualities-of-people-with-high-emotional-intelligence.html

Sarani A., Mousavi, S.H., Salahi, S., Hasani, F., Abdar, Z.E., \& Sheikhbardsiri, H. (2020). Emotional Intelligence and Self-Efficacy among deputy's administrative staff of Kerman University of Medical Sciences. Journal of Education and Health Promotion, 9, 105. DOI:10.4103/jehp.jehp_482_19

Sidhu, R.K. (2014). Emotional Intelligence in Relation to Performance of Teaching Professionals in Management and Technical Institutions. [Ph.D. Thesis]. Retrieved from http://hdl.handle.net/10603/54459

Woolfolk, A. (2004). Educational Psychology (9th Ed., pp. 486-487). Delhi: Pearson Education. 